\title{
KEANEKARAGAMAN JENIS TUMBUHAN PEKARANGAN YANG TERDAPAT DI KEMUKIMAN LUENG PUTU KECAMATAN BANDAR BARU KABUPATEN PIDIE JAYA
}

\author{
Zufahmi $^{(1)}$, Ervina Dewi ${ }^{(2)}$, Maulinda ${ }^{(3)}$ \\ ${ }^{1,2,3}$ Progrm Studi Pendidikan Biologi, Universitas Jabal Ghafur - Aceh \\ Email : zufahmibio@gmail.com
}

\begin{abstract}
ABSTRAK
Penelitian ini berjudul "Keanekaragaman Jenis Tumbuhan Pekarangan yang terdapat di Kemukiman Lueng Putu Kecamatan Bandar Baru Kabupaten Pidie Jaya", penelitian ini bertujuan untuk mengetahui keanekaragaman jenis tumbuhan pekarangan di kemukiman Lueng Putu. Penelitian ini menggunakan metode survey Eksploratif dengan metode Simple random sampling. Analisis data ditentukan dengan Indeks Keanekaragaman. Hasil penelitian menunjukkan terdapat 79 jenis tumbuhan yang termasuk kedalam 34 Famili. Indeks keanekaragaman jenis tumbuhan pekarangan yang ditemukan di Kemukiman Lueng Putu tergolong kriteria tinggi yaitu $H^{\prime}=3,465$.
\end{abstract}

Kata kunci: Keanekaragaman, Tumbuhan, Pekarangan

\section{PENDAHULUAN}

Indonesia merupakan negara kepulauan yang terletak dikawasan Khatulistiwa dan dikenal sebagai salah satu negara pemilik hutan tropika terluas dengan tingkat keanekaragaman yang tinggi. Salah satu kepulauan yang ada di Indonesia yang mempunyai keanekaragaman hayati adalah pulau Sumatera, khususnya Provinsi Aceh yang terletak diujung pulau Sumatera dan merupakan provinsi paling barat di Indonesia. Sebagian besar penduduk menggantungkan hidupnya dari hasil pertanian dan hutan. Namun, sebagian tanah atau lahan yang diupayakan sebagai areal pertanian sangat tergantung pada faktor yang dikendalikan oleh perubahan musim dan daya dukung lahan. Pada dasarnya usaha budidaya tumbuhan merupakan suatu kegiatan vital dalam kelangsungan hidup manusia yang menggunakan hasil tumbuhan sebagai bahan makanan utama dan untuk keperluan lain.
Semakin pesatnya pembangunan dan meningkatnya jumlah penduduk, maka kebutuhan pangan semakin meningkat, sedangkan luas lahan pertanian semakin sempit, sehingga salah satu alternatif yang digunakan untuk mengatasi masalah tersebut adalah dengan memanfaatkan lahan pekarangan ( Sulardi, 2010:1)

Pekarangan didefinisikan sebagai sebidang tanah yang mempunyai batas-batas tertentu, yang diatasnya terdapat bangunan tempat tinggal. Peranan dan pemanfaatan pekarangan bervariasi dari satu daerah dengan daerah lainnya, tergantung pada tingkat kebutuhan, sosial budaya, pendidikan masyarakat maupun faktor fisik dan ekologi setempat. Di Indonesia, peranan pekarangan belum mendapat perhatian sepenuhnya, padahal jika dikelola dengan baik bukan tidak mungkin akan menambah penghasilan keluarga (Rahayu, 2005: 360). 
Kemukiman Lueng Putu merupakan suatu Kemukiman yang berada di Kecamatan Bandar Baru, Kabupaten Pidie Jaya, Provinsi Aceh. Kemukiman ini Terdiri dari 5 desa yaitu Keude Lueng putu, Blang Glong, Tutong, Siren, dan Pueb Lueng Nibong. Mata pencarian utama adalah pada sektor pertanian dibandingkan dengan mata pencaharian lainnya yang terdiri dari Guru, Berdagang dan Wiraswasta. Bertani merupakan kegiatan turun temurun yang dilakukan oleh penduduk setempat (Gita, 2018: 66).

Pertambahan jumlah penduduk setiap tahun menyebabkan meningkatnya lahan yang digunakan untuk pembangunan perumahan penduduk. Pekarangan di Kemukiman Lueng Putu semakin berkurang karena banyak area yang digunakan untuk pembangunan, ditambah lagi dengan adanya perluasan jalan yang menyebabkan area pekarangan ikut terganggu. Hal ini dapat mengurangi luas lahan hijau yang sangat diperlukan didaerah tersebut terutama lahan pekarangan. Penduduk pada desa setempat mayoritas memiliki area pekarangan dengan kategori pekarangan sedang dan luas. Pekarangan tersebut umumnya ditanami berbagai jenis tanaman buah- buahan dan tanaman hias. Namun demikian, penelitian tanaman pekarangan khususnya di daerah Kemukiman Lueng Putu ini belum pernah dilakukan, sehingga perlu dilakukan penelitian untuk dapat melengkapi data keanekaragaman jenis tanaman pekarangan (Hasil Observasi, 2019).

\section{Rumusan masalah}

Rumusan Masalah pada penelitian ini adalah Bagaimanakah keanekaragaman jenis tumbuhan pekarangan yang terdapat di
Kemukiman Lueng Putu Kecamatan Bandar Baru Kabupaten Pidie Jaya?

\section{Tujuan Penelitian}

Penelitian ini bertujuan Untuk mengetahui keanekaragaman jenis tumbuhan pekarangan di Kemukiman Lueng Putu Kecamatan Bandar Baru Kabupaten Pidie Jaya.

\section{Manfaat Penelitian}

Manfaat yang diharapkan setelah melakukan penelitian ini adalah sebagai berikut:

a. Sebagai bahan informasi untuk mengetahui keanekaragaman jenis tumbuhan pekarangan di Kemukiman Lueng Putu Kecamatan Bandar Baru Kabupaten Pidie Jaya.

b. Sebagai data untuk melengkapi keanekaragaman jenis tumbuhan pekarangan

\section{METODE PENELITIAN}

\subsection{Tempat dan Waktu}

Penelitian ini dilaksanakan pada bulan Agustus 2019 di Kemukiman Lueng Putu Kecamatan Bandar Baru Kabupaten Pidie Jaya yang terdiri dari 5 desa yaitu Desa Keude Lueng Putu, Desa Blang Glong, Desa Tutong, Desa Siren, dan Desa Pueb- Lueng Nibong.

\subsection{Alat dan Bahan}

Alat yang digunakan dalam penelitian ini adalah Alat tulis, Kamera. Bahan yang digunakan adalah buku tulis, Lembar Pengamatan dan tumbuhan pekarangan yang terdapat dilokasi penelitian.

\subsection{Metode Penelitian}

Jenis penelitian yang digunakan untuk memperoleh data lapangan adalah metode Survey Eksploratif. Penelitian eksploratif adalah suatu metode observasi langsung tempat penelitian dilakukan (Abdurrahmat, 2011: 99). 
Penelitian ini dilakukan dengan menjelajahi dan mengamati secara langsung jenis tumbuhan pekarangan. Metode pengambilan sampel yang digunakan adalah Simple Random Sampling yaitu pengambilan sampel dari populasi dilakukan secara acak tanpa memperhatikan strata yang ada dalam populasi tersebut (Sugiyono, 2008:120).

\subsection{Prosedur Penelitian}

1. Lokasi penelitian

Sebelum melakukan penelitian terlebih dahulu telah dilakukan observasi lapangan untuk mengamati secara langsung kondisi lapangan untuk memudahkan dalam menetapkan tempat dari lokasi penelitian. Lokasi penelitian terletak di Kemukiman Lueng Putu Kecamatan Bandar Baru Kabupaten Pidie Jaya.

2. Pengumpulan Sampel

Tumbuhan Pekarangan

Pengumpulan data dilakukan menggunakan metode jelajah dengan cara menyisir semua lokasi yang telah ditentukan, jenis tumbuhan yang ditemukan kemudian difoto untuk dilakukan proses pengidentifikasian.

3. Identifikasi Sampel

Tumbuhan Pekarangan yang terdapat ditempat pengamatan dicatat pada tabel (lembar kerja yang telah disediakan) dan diidentifikasi nama daerah beserta nama ilmiahnya kemudian dihitung jumlah individunya. Tumbuhan yang belum jenisnya akan diidentifikasi lebih lanjut.

4. Klasifikasi spesimen

Hasil pengindentifikasian spesimen tumbuhan pekarangan yang diketahui nama jenisnya kemudian diklasifikasi berdasarkan tingkatan takson yang meliputi kingdom, devisio, kelas, ordo, familia, genus, spesies.

\subsection{Analisis Data}

Data hasil penelitian dianalisis secara deskriptif dengan menghitung indeks keragaman menggunakan rumus .

\section{Indeks Keanekaragaman Shannon-} Wiener $\left(H^{\prime}\right)$

dengan:

$$
\begin{aligned}
& H^{\prime}=-\sum \text { pi ln pi } \\
& \text { pi }=\text { ni/ } N
\end{aligned}
$$

$H^{\prime}=$ Indeks Keanekaragaman Shannon-

Wiener

$p i=$ Proporsi jumlah individu ke-1

dengan jumlah total individu

ni $=$ Spesies ke- 1

$\mathrm{N}$ = Jumlah total individu

Dengan kriteria indeks keanekaragaman sebagai berikut:

$$
\begin{array}{ll}
\mathrm{H}>3 & =\text { Tinggi } \\
1<\mathrm{H}<3 & =\text { Sedang } \\
\mathrm{H}<1 & =\text { Rendah }
\end{array}
$$

\section{HASIL DAN PEMBAHASAN}

Keanekaragaman jenis Tumbuhan Pekarangan di Kemukiman Lueng Putu Kecamatan Bandar baru Kabupaten Pidie Jaya

Berdasarkan hasil penelitian yang telah dilaksanakan di Kemukiman Lueng Putu Kecamatan Bandar Baru Kabupaten Pidie Jaya di dapatkan 79 spesies tumbuhan. Keanekaragaman jenis tumbuhan dapat dilihat pada Tabel 4.1 sebagai berikut:

Tabel 4.1. Keanekaragaman Jenis Tumbuhan Pekarangan diKemukiman Keude Lueng Putu Kecamatan Bandar Baru Kabupaten Pidie Jaya

\begin{tabular}{|l|l|l|l|l|}
\hline No & $\begin{array}{l}\text { Nama } \\
\text { daerah }\end{array}$ & $\begin{array}{l}\text { Nama } \\
\text { ilmiah }\end{array}$ & Famili & Jumlah \\
\hline 1 & Mawar & $\begin{array}{l}\text { Rosa } \\
\text { hybrida }\end{array}$ & Rosaceae & 60 \\
\hline 2 & Melati & $\begin{array}{l}\text { Jasminum } \\
\text { sambac L }\end{array}$ & Olaceae & 35 \\
\hline 3 & Kamboja & Plumeria & Apocynaceae & 28 \\
\hline
\end{tabular}


JAR, Volume 3 Nomor 2 Agustus 2020 $p$-ISSN 2615-417X, $e$-ISSN 2721-0782

\begin{tabular}{|c|c|c|c|c|}
\hline & & $\begin{array}{l}\text { acuminata } \\
\text { Ait. }\end{array}$ & & \\
\hline 4 & Asoka & $\begin{array}{l}\text { Saraca } \\
\text { asoca }\end{array}$ & Fabaceae & 80 \\
\hline 5 & $\begin{array}{l}\text { Bunga } \\
\text { kertas }\end{array}$ & $\begin{array}{l}\text { Bougainvill } \\
\text { ea glabra }\end{array}$ & $\begin{array}{l}\text { Nyctaginacea } \\
\mathrm{e}\end{array}$ & 130 \\
\hline 6 & $\begin{array}{l}\text { Bunga } \\
\text { pukul } \\
\text { sembilan }\end{array}$ & $\begin{array}{l}\text { Portulaca } \\
\text { grandiflora }\end{array}$ & Portulaceae & 80 \\
\hline 7 & $\begin{array}{l}\text { Nona } \\
\text { makan } \\
\text { sirih }\end{array}$ & $\begin{array}{l}\text { Clerodendr } \\
\text { um } \\
\text { thomsoniae } \\
\text { Balf.F. }\end{array}$ & Lamiaceae & 10 \\
\hline 8 & $\begin{array}{l}\text { Lidah } \\
\text { mertua }\end{array}$ & $\begin{array}{l}\text { Sansevieria } \\
\text { trifasciata } \\
\text { Var. }\end{array}$ & Draceanaceae & 128 \\
\hline 9 & $\begin{array}{l}\text { Lidah } \\
\text { buaya }\end{array}$ & Aloe vera & $\begin{array}{l}\text { Xanthorrhoae } \\
\text { aceae }\end{array}$ & 16 \\
\hline 10 & $\begin{array}{l}\text { Bunga } \\
\text { Kupu- } \\
\text { kupu }\end{array}$ & $\begin{array}{l}\text { Bauhinia } \\
\text { purpurea } \mathrm{L}\end{array}$ & Fabaceae & 30 \\
\hline 11 & Dahlia & $\begin{array}{l}\text { Dahlia } \\
\text { pinnata }\end{array}$ & Asteraceae & 23 \\
\hline 12 & $\begin{array}{l}\text { Tahi } \\
\text { ayam }\end{array}$ & $\begin{array}{l}\text { Tagetes } \\
\text { erecta } L\end{array}$ & Verbenaceae & 106 \\
\hline 13 & $\begin{array}{l}\text { Jengger } \\
\text { ayam }\end{array}$ & $\begin{array}{l}\text { Celosia } \\
\text { cristata }\end{array}$ & $\begin{array}{l}\text { Amaranthace } \\
\text { ae }\end{array}$ & 27 \\
\hline 14 & $\begin{array}{l}\text { Ekor } \\
\text { kucing }\end{array}$ & $\begin{array}{l}\text { Acalypha } \\
\text { hispida }\end{array}$ & $\begin{array}{l}\text { Euphorbiacea } \\
\mathrm{e}\end{array}$ & 21 \\
\hline 15 & Matahari & $\begin{array}{l}\text { Helianthus } \\
\text { annuus }\end{array}$ & Asteraceae & 3 \\
\hline 16 & Kaktus & $\begin{array}{l}\text { Euphorbia } \\
\text { milli }\end{array}$ & Cactaceae & 1 \\
\hline 17 & Anggrek & $\begin{array}{l}\text { Phalaepnos } \\
\text { is amabilis }\end{array}$ & Orchidaceae & 8 \\
\hline 18 & Pacar air & $\begin{array}{l}\text { Impantien } \\
\text { balsamina }\end{array}$ & $\begin{array}{l}\text { Balsaminacea } \\
\mathrm{e}\end{array}$ & 89 \\
\hline 19 & $\begin{array}{l}\text { Adam } \\
\text { hawa }\end{array}$ & $\begin{array}{l}\text { Rhoeo } \\
\text { discolor }\end{array}$ & $\begin{array}{l}\text { Commelinace } \\
\text { ae }\end{array}$ & 30 \\
\hline 20 & Jambu air & $\begin{array}{l}\text { Syzygium } \\
\text { aquem }\end{array}$ & Myrtaceae & 39 \\
\hline 21 & $\begin{array}{l}\text { Jambu } \\
\text { biji }\end{array}$ & $\begin{array}{l}\text { Psidium } \\
\text { gujava }\end{array}$ & Myrtaceae & 32 \\
\hline 22 & $\begin{array}{l}\text { Jambu } \\
\text { madu }\end{array}$ & $\begin{array}{l}\text { syzygiumsa } \\
\text { marangens } \\
e\end{array}$ & Myrtaceae & 14 \\
\hline 23 & Mangga & $\begin{array}{l}\text { Mangifera } \\
\text { indics }\end{array}$ & $\begin{array}{l}\text { Anacardiacea } \\
\mathrm{e}\end{array}$ & 85 \\
\hline 24 & $\begin{array}{l}\text { Rambuta } \\
\mathrm{n}\end{array}$ & $\begin{array}{l}\text { Nephelium } \\
\text { lappaceum }\end{array}$ & Sapindaceae & 34 \\
\hline 25 & Sawo & $\begin{array}{l}\text { Manilkara } \\
\text { zapota }\end{array}$ & Sapotaceae & 14 \\
\hline 26 & Pisang & $\begin{array}{l}\text { Musa } \\
\text { paradisiaca }\end{array}$ & Musaceae & 44 \\
\hline 27 & Pepaya & $\begin{array}{l}\text { Carica } \\
\text { pepaya }\end{array}$ & Caricaceae & 49 \\
\hline 28 & Melinjo & $\begin{array}{l}\text { Gnetum } \\
\text { gnemon }\end{array}$ & Gnetaceae & 43 \\
\hline 29 & Coklat & $\begin{array}{l}\text { Theobrama } \\
\text { cacao }\end{array}$ & Malvaceae & 6 \\
\hline 30 & $\begin{array}{l}\text { Jeruk } \\
\text { nipis }\end{array}$ & $\begin{array}{l}\text { Citrus } \\
\text { aurantifolia }\end{array}$ & Rutaceae & 7 \\
\hline 31 & $\begin{array}{l}\text { Jeruk } \\
\text { lemon }\end{array}$ & $\begin{array}{l}\text { Citrus } \\
\text { amblycarpa }\end{array}$ & Rutaceae & 5 \\
\hline 32 & $\begin{array}{l}\text { Jeruk } \\
\text { purut }\end{array}$ & $\begin{array}{l}\text { Citrus } \\
\text { hystrix Dc. }\end{array}$ & Rutaceae & 8 \\
\hline 33 & $\begin{array}{l}\text { Jeruk } \\
\text { manis }\end{array}$ & $\begin{array}{l}\text { Citrus } \\
\text { sinensis }\end{array}$ & Rutaceae & 2 \\
\hline 34 & $\begin{array}{l}\text { Belimbin } \\
\mathrm{g} \text { wuluh }\end{array}$ & $\begin{array}{l}\text { Averrhoa } \\
\text { bilimbi }\end{array}$ & Oxalidaceae & 60 \\
\hline 35 & Belimbin & Averrhoa & Oxalidaceae & 1 \\
\hline
\end{tabular}

\begin{tabular}{|c|c|c|c|c|}
\hline & $\mathrm{g}$ manis & carambola & & \\
\hline 36 & Puring & $\begin{array}{l}\text { Codiaeum } \\
\text { variegatum } \\
\text { L. }\end{array}$ & $\begin{array}{l}\text { Euphorbiacea } \\
\text { e }\end{array}$ & 136 \\
\hline 37 & Kelapa & $\begin{array}{l}\text { Cocos } \\
\text { nucifera }\end{array}$ & Arecaceae & 55 \\
\hline 38 & $\begin{array}{l}\text { Cabai } \\
\text { merah }\end{array}$ & $\begin{array}{l}\text { Capsicum } \\
\text { annum }\end{array}$ & Solanaceae & 34 \\
\hline 39 & $\begin{array}{l}\text { Cabai } \\
\text { rawit }\end{array}$ & $\begin{array}{l}\text { Capsicum } \\
\text { frutescens } \\
\text { L. }\end{array}$ & Solanaceae & 32 \\
\hline 40 & Bayam & $\begin{array}{l}\text { Amaranthu } \\
s L\end{array}$ & $\begin{array}{l}\text { Amaranthace } \\
\text { ae }\end{array}$ & 15 \\
\hline 41 & Kelor & $\begin{array}{l}\text { Moringa } \\
\text { oleifera L. }\end{array}$ & Moringaceae & 2 \\
\hline 42 & Tomat & $\begin{array}{l}\text { Solanum } \\
\text { lycopersicu } \\
\text { m L. }\end{array}$ & Solanaceae & 12 \\
\hline 43 & Delima & $\begin{array}{l}\text { Punica } \\
\text { granatum }\end{array}$ & Lythraceae & 2 \\
\hline 44 & Singkong & $\begin{array}{l}\text { Manihot } \\
\text { utilissima }\end{array}$ & $\begin{array}{l}\text { Euphorbiacea } \\
\text { e }\end{array}$ & 14 \\
\hline 45 & Naga & $\begin{array}{l}\text { Hylocereus } \\
\text { cistericensi }\end{array}$ & Cactaceae & 10 \\
\hline 46 & Labu air & $\begin{array}{l}\text { Lagenaria } \\
\text { siceraria }\end{array}$ & Cucurbitaceae & 7 \\
\hline 47 & $\begin{array}{l}\text { Pucuk } \\
\text { merah }\end{array}$ & $\begin{array}{l}\text { Syzygium } \\
\text { oleana }\end{array}$ & Myrtaceae & 10 \\
\hline 48 & Kunyit & $\begin{array}{l}\text { Curcuma } \\
\text { domestika } \\
\text { Val. } \\
\end{array}$ & Zingeberceae & 7 \\
\hline 49 & Sirih & Piper betle & Piperaceae & 11 \\
\hline 50 & Serai & $\begin{array}{l}\text { Cymbopogo } \\
n \text { citratus }\end{array}$ & Poaceae & 10 \\
\hline 51 & Pinang & $\begin{array}{l}\text { Areca } \\
\text { catechu }\end{array}$ & Arecaceae & 20 \\
\hline 52 & Nangka & $\begin{array}{l}\text { Arthocarpu } \\
s \quad \text { integra } \\
\text { Merr. }\end{array}$ & Moraceae & 6 \\
\hline 53 & $\begin{array}{l}\text { Terong } \\
\text { ungu }\end{array}$ & $\begin{array}{l}\text { Solanum } \\
\text { melongena } \\
\mathrm{L}\end{array}$ & Solanaceae & 3 \\
\hline 54 & Kopi & $\begin{array}{l}\text { Coffea } \\
\text { arrabica }\end{array}$ & Rubiaceae & 1 \\
\hline 55 & $\begin{array}{l}\text { Bunga } \\
\text { bawang } \\
\text { merah } \\
\text { jambu }\end{array}$ & $\begin{array}{l}\text { Zephyranth } \\
\text { es minuta }\end{array}$ & $\begin{array}{l}\text { Amarylidacea } \\
\mathrm{e}\end{array}$ & 29 \\
\hline 56 & $\begin{array}{l}\text { Pandan } \\
\text { wangi }\end{array}$ & $\begin{array}{l}\text { Pandanus } \\
\text { amaryllifoli } \\
\text { us }\end{array}$ & Pandanaceae & 17 \\
\hline 57 & $\begin{array}{l}\text { Jarak } \\
\text { pagar }\end{array}$ & $\begin{array}{l}\text { Jatropha } \\
\text { curcas }\end{array}$ & $\begin{array}{l}\text { Euphorbiacea } \\
\mathrm{e}\end{array}$ & 14 \\
\hline 58 & $\begin{array}{l}\text { Daun } \\
\text { kari }\end{array}$ & $\begin{array}{l}\text { Muraya } \\
\text { koenigii }\end{array}$ & Rutaceae & 12 \\
\hline 59 & $\begin{array}{l}\text { Kembang } \\
\text { merak }\end{array}$ & $\begin{array}{l}\text { Caesalpinia } \\
\text { pulcherrim } \\
a\end{array}$ & Fabaceae & 4 \\
\hline 60 & $\begin{array}{l}\text { Kembang } \\
\text { sepatu }\end{array}$ & $\begin{array}{l}\text { Hibiscus } \\
\text { rosa- } \\
\text { sinensis }\end{array}$ & Malvaceae & 20 \\
\hline 61 & Nanas & $\begin{array}{l}\text { Ananas } \\
\text { comosus } \mathrm{L}\end{array}$ & Bromeliaceae & 2 \\
\hline 62 & Waru & $\begin{array}{l}\text { Talipariti } \\
\text { tiliaceum } \mathrm{L}\end{array}$ & Malvaceae & 5 \\
\hline 63 & $\begin{array}{l}\text { Kelengke } \\
\text { ng }\end{array}$ & $\begin{array}{l}\text { Dimocarpu } \\
\text { s longan } \mathrm{L}\end{array}$ & Sapindaceae & 3 \\
\hline 64 & Gadung & $\begin{array}{l}\text { Dioscorea } \\
\text { hispida }\end{array}$ & $\begin{array}{l}\text { Dioscoreacea } \\
\mathrm{e}\end{array}$ & 1 \\
\hline 64 & $\begin{array}{l}\text { Lonceng } \\
\text { ungu/ }\end{array}$ & $\begin{array}{l}\text { Ruellia } \\
\text { simplex }\end{array}$ & Acanthoideae & 7 \\
\hline
\end{tabular}




\begin{tabular}{|c|c|c|c|c|}
\hline & kencana & & & \\
\hline 65 & Tebu & $\begin{array}{l}\text { Saccharum } \\
\text { officinarum }\end{array}$ & Poaceae & 9 \\
\hline 66 & Sirsak & $\begin{array}{l}\text { Annona } \\
\text { muricata }\end{array}$ & Annonaceae & 2 \\
\hline 67 & Seledri & $\begin{array}{l}\text { Apium } \\
\text { graveolens }\end{array}$ & Apiaceae & 41 \\
\hline 68 & $\begin{array}{l}\text { Tanaman } \\
\text { daun } \\
\text { dolar }\end{array}$ & $\begin{array}{l}\text { Zamioculca } \\
\text { s zamifolia }\end{array}$ & Moraceae & 8 \\
\hline 69 & Sukun & $\begin{array}{l}\text { Artocarpus } \\
\text { altilis }\end{array}$ & Moraceae & 3 \\
\hline 70 & $\begin{array}{l}\text { Mengkud } \\
\mathrm{u}\end{array}$ & $\begin{array}{l}\text { Morinda } \\
\text { citrifolia }\end{array}$ & Rubiaceae & 1 \\
\hline 71 & $\begin{array}{l}\text { Sirih } \\
\text { merah }\end{array}$ & $\begin{array}{l}\text { Piper } \\
\text { ornatum }\end{array}$ & Piperaceae & 2 \\
\hline 72 & Durian & $\begin{array}{l}\text { Durio } \\
\text { zibethinus }\end{array}$ & Malvaceae & 1 \\
\hline 73 & $\begin{array}{l}\text { Mahkota } \\
\text { dewa }\end{array}$ & $\begin{array}{l}\text { Phaleria } \\
\text { macrocarp } \\
\text { a }\end{array}$ & $\begin{array}{l}\text { Thymelaecea } \\
\text { e }\end{array}$ & 1 \\
\hline 74 & $\begin{array}{l}\text { Kedondo } \\
\text { ng }\end{array}$ & $\begin{array}{l}\text { Spondias } \\
\text { dulcis }\end{array}$ & $\begin{array}{l}\text { Anacardiacea } \\
\mathrm{e}\end{array}$ & 1 \\
\hline 75 & Keladi & $\begin{array}{l}\text { Lasia } \\
\text { spinosa }\end{array}$ & Araceae & 236 \\
\hline 76 & Iler & $\begin{array}{l}\text { Plectranthu } \\
\text { s } \\
\text { scutellarioi } \\
\text { des } \mathrm{L}\end{array}$ & Lamiaceae & 28 \\
\hline 77 & $\begin{array}{l}\text { Asam } \\
\text { jawa }\end{array}$ & $\begin{array}{l}\text { Tamarindus } \\
\text { indica }\end{array}$ & Fabaceae & 1 \\
\hline 78 & $\begin{array}{l}\text { Bunga } \\
\text { pukul } 4\end{array}$ & $\begin{array}{l}\text { Mirabilis } \\
\text { jalapa }\end{array}$ & $\begin{array}{l}\text { Nyctaginacea } \\
\text { e }\end{array}$ & 8 \\
\hline 79 & $\begin{array}{l}\text { Bunga } \\
\text { kancing }\end{array}$ & $\begin{array}{l}\text { Gomphrena } \\
\text { globosa } \mathrm{L}\end{array}$ & $\begin{array}{l}\text { Amaranthace } \\
\text { ae }\end{array}$ & 10 \\
\hline & \multicolumn{3}{|c|}{ Jumlah total } & $\begin{array}{l}2,20 \\
1\end{array}$ \\
\hline
\end{tabular}

(Hasil Penelitian, 2019)

Dari hasil penelitian yang telah dilakukan di Kemukiman Lueng Putu Kecamatan Bandar Baru Kabupaten Pidie Jaya ditemukan 79 jenis tumbuhan yang termasuk dalam 34 famili yaitu Apocynaceae,

Anacardiaceae,

Sapindaceae, Rutaceae, Rosaceae, Olaceae, Amaranthaceae, Verbenaceae, Nyctaginaceae,

Pandanaceae, Gnetaceae, Musaceae, Annonaceae, Solanaceae, Orchidaceae, Malvaceae, Asteraceae, Fabaceae, Euphorbiaceae, Commelinaceae, Myrtaceae, Arecaceae, Caricaceae, Apiaceae, Portulaceae, Piperaceae, Lamiaceae, Oxalidaceae, Araceae, Bromeliaceae, Bombacacaceae, Zingeberceae, Rutaceae, Balsaminaceae. Jumlah total individu dari keseluruhan spesies yang berada di Kemukiman Lueng Putu
Kecamatan Bandar Baru Kabupaten Pidie Jaya berjumlah 2,201 individu.

Indeks Keanekaragaman ( $\left.H^{\prime}\right)$ Keanekaragaman Jenis Tumbuhan Pekarangan di Kemukiman Lueng Putu Kecamatan Bandar Baru Kabupaten Pidie Jaya.

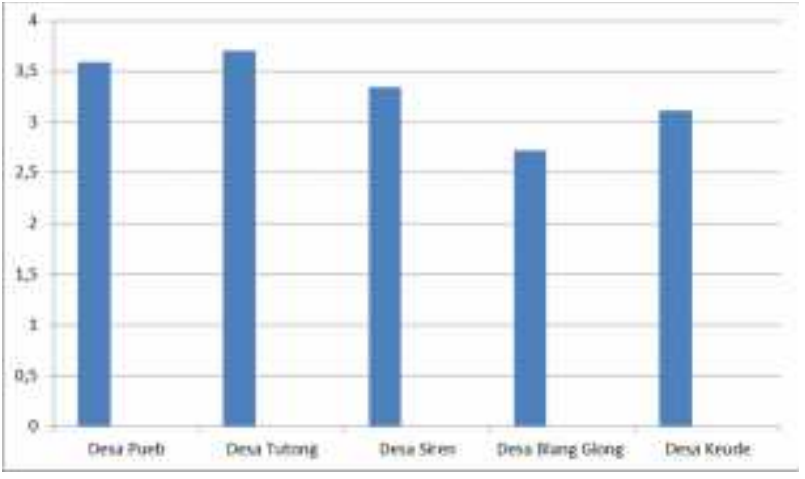

Gambar 4.1: Diagram keanekaragaman $H^{\prime}$ Jenis tumbuhan Pekarangan di Kemukiman Lueng Putu Kecamatan Bandar Baru Kabupaten Pidie Jaya.

Hasil indeks keanekaragaman $\left(H^{\prime}\right)$ jenis tumbuhan pekarangan yang ditemukan di Kemukiman Lueng Putu Kecamatan Bandar Baru Kabupaten Pidie Jaya termasuk dalam tingkatan sedang dan tinggi. Desa Pueb Lueng Nibong dengan nilai 3,359, Tutong 3,701, Siren 3,345, Blang Glong 2,722, dan Keude 3,11. Pada penelitian ini tingkat keanekaragaman jenis tumbuhan pekarangan di Kemukiman Lueng Putu Kecamatan Bandar Baru Kabupaten Pidie Jaya tergolong tinggi.

\section{Pembahasan}

Berdasarkan hasil penelitian yang dilakukan di Kemukiman Lueng Putu Kecamatan Bandar Baru Kabupaten Pidie Jaya ditemukan 79 jenis tumbuhan yang tergolong dalam 34 famili. Tumbuhan yang ditemukan terdiri dari beranekaragam jenis tumbuhan pekarangan seperti tumbuhan berbuah, tanaman hias dan sayuran. Tumbuhan pekarangan seperti buah dan 
sayuran dapat dimanfaatkan sebagai kebutuhan sehari- hari, sedangkan tanaman hias dapat meningkatkan keindahan pekarangan rumah. Pada saat musim kemarau tumbuhan berbuah di Kemukiman Lueng Putu Kecamatan Bandar Baru Kabupaten Pidie Jaya tumbuhan tersebut tetap berbuah lebat hal ini disebabkan karena tanah yang subur dan sumber air tanah yang cukup. Menurut (Arifin, 2013:6 ) beragam strata tanaman dalam pekarangan dapat memanen energi matahari serta menyerap karbon secara efektif, melindungi tata tanah dan tata air, serta memberikan keindahan dan kenyamanan lingkungan setempat.

Lokasi penelitian merupakan kawasan pemukiman yang padat penduduk sehingga memiliki pekarangan yang sedang dan cukup luas. Pada umumnya diberi pembatas kayu sebagai pemisah antara pekarangan rumah yang satu dengan lainnya. Oleh karena itu keanekaragaman tumbuhan pekarangan di Kemukiman Lueng Putu Kecamatan Bandar Baru Kabupaten Pidie Jaya termasuk kategori tinggi.

Keanekaragaman

atau biodiversitas merupakan variasi atau perbedaan bentuk- bentuk makhluk hidup, meliputi perbedaan pada tumbuhan, hewan, mikroorganisme, materi genetik serta bentuk-bentuk ekosistem tempat hidup suatu makhluk hidup (Ridhwan, 2012:1). Keanekaragaman tumbuhan di pekarangan merupakan bagian dari keanekaragaman hayati yang dimiliki oleh masyarakat. Keanekaragaman tumbuhan menciptakan pelestarian lingkungan hidup pada pekarangan sehingga pekarangan berperan penting dalam memenuhi kebutuhan sehari-hari. Menurut (Feriatin 2017: 99), peranan dan pemanfaatan pekarangan bervariasi dari satu daerah ke daerah lainnya, hal ini tergantung pada tingkat kebutuhan, sosial budaya, tingkat pendidikan, faktor fisik serta ekologi setempat. Pemanfaatan pekarangan merupakan hal yang sangat strategis dalam konteks mengkonservasi keanekaragaman hayati pertanian untuk beragam jenis tanaman, hewan, dan ikan. Selanjutnya menurut (Nurwati, 2015:1-2) mengatakan bahwa lahan pekarangan merupakan lahan yang berada di sekitar rumah yang biasanya memiliki hubungan kepemilikan dengan pemilik rumah sehingga pemanfaatan lahan pekarangan rumah juga dipengaruhi oleh luasan pekarangan dan minat dari anggota keluarga tersebut.

Ada 3 macam kriteris nilai indeks keanekaragaman jenis yaitu, $H^{\prime}<$ 1 berarti keanekaragaman tergolong rendah, $H^{\prime}=1-3$ berarti keanekaragaman tergolong sedang, $H^{\prime}$ > 3 berarti keanekaragaman tergolong tinggi. Berdasarkan kriteria tersebut maka indeks keanekaragaman jenis tumbuhan yang terdapat dilokasi penelitian tergolong kategori sedang dan tinggi $\left(H^{\prime}>3\right)$.

\section{PENUTUP}

\subsection{Kesimpulan}

Berdasarkan hasil penelitian tentang jenis tumbuhan pekarangan di Kemukiman Lueng Putu, maka dapat disimpulkan sebagai berikut:

1. Terdapat 79 jenis tumbuhan yang termasuk dalam 34 famili tumbuhan pekarangan yang ditemukan di Kemukiman Lueng Putu Kecamatan Bandar Baru Kabupaten Pidie Jaya.

2. Indeks keanekaragaman ( $\left.H^{\prime}\right)$ jenis tumbuhan pekarangan di Kemukiman Lueng Putu Kecamatan Bandar Baru 
Kabupaten Pidie Jaya tergolong pada kriteria tinggi yaitu $H^{\prime}=3,465$.

\subsection{Saran}

Saran yang diajukan penulis pada penelitian ini yaitu sebagai berikut:

1. Agar penelitian ini dapat dikembangkan lagi dengan melakukan penelitian dilokasi yang lain untuk melengkapi data keanekaragaman sebagai ilmu pengetahuan.

2. Diharapkan agar dapat melakukan penelitian lanjutan untuk mengetahui lebih banyak jenis tumbuhan pekarangan sehingga dapat dikembangkan menjadi indeks kekayaan jenis dan indeks

keseragaman/kemerataan

\section{DAFTAR PUSTAKA}

Arifin, H. S. 2013. Pekarangan Kampung Untuk Konservasi Agro-Biodeversitas Dalam Mendukung

Penganekaragaman dan

Ketahanan Pangan di Indonesia. Orasi Ilmiah. Institut Pertanian Bogor, hal 138.

Abdurrahmat, F. 2011. Metodologi Penelitian Tekhnik Penyusunan Skripsi. Jakarta: Bineka Cipta.

Feriatin. 2017. Keanekaragaman Tanaman Pekarangan dan Pemanfaatannya untuk Mendukung Ketahanan Pangan Kecamatan Wakorumba Selatan. Jurnal Ilmu Pertanian Indonesia (JIPI), Vol 22(2): 99-107.
Gita Dwi, S. R. 2018. Jenis Tanaman Buah dan Sayur Pekarangan di Desa Sumberejo Ambulu Jember. Jurnal Biologi dan Pembelajaran Biologi. Vol 3(1): 65- 76.

Nurwati, N., Seprita Lidar., Mufti. 2015. Model Pemberdayaan Pekarangan Di Kecamatan Rumbai Pesisir Kota Pekan Baru. Jurnal Agribisnis. Vol 17(1): 1-10.

Rahayu, M., Suhardjono P. (2005). Keanekaragaman Tanaman Pekarangan dan Pemanfaatannya di Desa Lampeapi Pulau Wawoni Sulawesi Tenggara. Teknologi Lingkungan P3TLBPPT 6 (2):362- 364 .

Ridhwan, M. 2012. Tingkat Keanekaragaman Hayati Dan Pemanfaatannya di Indonesia. Jurnal Biology Education. Vol 1(1): 1- 4.

Sulardi. 2010. Tingkat Kerapatan Dan Pola Pemetaan Tanaman Pekarangan Di Kecamatan Kaliwungu Kabupaten Semarang Jawa Tengah. Skripsi. Universitas Muhammadiyah. Surakarta.

Sugiono. 2008. Metode Penelitian Pendidikan (Pendekatan Kuantitatif, Kualitatif dan $R \& D)$. Bandung: Alfabeta. 